\title{
El autoaprendizaje y la asimilación de conocimiento en organizaciones empresariales
}

\author{
Marín González, Freddy*
}

\section{Resumen}

La investigación tiene como propósito fundamental aproximarse a la construcción de explicaciones de orden teórico - conceptual relacionadas con el autoaprendizaje y la asimilación de conocimiento en organizaciones del sector empresarial. Se asume la producción y transferencia de conocimiento como un proceso cíclico que parte del individuo y que puede ocurrir de manera integrada y complementaria entre espacios del sistema social. En correspondencia con este propósito de intención explicativa y demostrativa, se transfieren los elementos característicos de ciertas imágenes metafóricas y de la perspectiva biológica evolucionista, para analizar el proceso. El método de investigación de naturaleza lógico-formal que se aplica básicamente es la inferencia abductiva, complementado con la metáfora como metodología que a través de un proceso de transferencia y analogía, permi te explicar el comportamiento de las organizaciones del sector empresarial. Se infiere como principal resultado una serie de hipótesis explicativas entre las que se destaca: las diferentes formas de pensamiento de los actores organizacionales contribuyen a interpretar y comprender las situaciones específicas del comportamiento organizacional en relación con el consumo de conocimiento. Se concluye que la aplicación de ese método permite contribuir a la generación de explicaciones en relación con la teoría organizacional.

Palabras clave: Conocimiento, asimilación, autoaprendizaje, organizaciones del sector empresarial.

Recibido: 01-12-12 . Aceptado: 02-05-06

Licenciado en Educación, Especialista y Magíster en Planificación y Administración Educativa (LUZ), Alumno regular del Programa de Doctorado en Ciencias Humanas de La Universidad del Zulia. Profesor Asociado a Dedicación Exclusiva de La Universidad del Zulia, Núcleo Punto Fijo. Acreditado ante el SVPI (Nivel Candidato). E-mail: fvmarin@luz.ve.

Celular 0414 - 6931940; Tele-fax 0261-7598085; Teléfono 0269 - 2450512 


\section{Self-Learning and the Assimlation of Knowledge in Business Organizations}

\section{Abstract}

The fundamental purpose of research is to focus on the construction of technical explanations of a technical-conceptual nature related to self-learning and the assimilation of knowledge of organizations in the business sector. Production and transferal of knowledge are assumed to be cyclical processes that begin with the individual and which can occur in an integrated and complementary manner within the social system space. Corresponding to this purpose of an explanatory and demonstrative nature, the characteristic elements of certain metaphorical images and the evolutionist biological perspective are transferred to the analysis of the process. The logical-formal research method that is applied is basically abducted inference, complemented by the metaphor, which through a process of transference and analogy allows us to explain the behavior of business sector organizations. A series of explanatory hypothesis are inferred to among which we highlight the distinct manners of thought of organizational actors which contribute to the interpretation and comprehension of specific organizational behavior in relation to knowledge consumption situations. The conclusion is that the application of this method offers a contribution to the generation of explanations in relation to organization theory.

Key words: Knowledge, assimilation, self-learning, business sector organizations.

\section{Introducción}

Las grandes transformaciones que está experimentando el ser humano y el contexto social conducen a la necesidad de ir repensando la forma como suceden los principales procesos que caracterizan a las personas, de tal manera que se logre una amplia comprensión de los mismos. Por tanto, resulta imperativo atender la forma en que el hombre como individualidad o miembro de una organización internaliza la ocurrencia de procesos que forman parte de su condición de existencia, y que muchas veces, quizás por no sentir interés o simplemente por desconocimiento no se detiene a analizar y a construir ciertas explicaciones a partir de su comportamiento histórico-concreto en el tiempo. Tal es el caso de la producción y transferencia de conocimiento entre individuos y organizaciones del sistema social.

Lo antes planteado se corresponde con la emergencia del paradigma científico-técnico característico de la sociedad del conocimiento que está demarcando e influenciando el comportamiento de las organizaciones. En el contexto de lo referido resulta importante analizar las nuevas tendencias que presenta la organización empresarial, que aunque tienen una base económica, penetran otras motivaciones como las relacionadas con las demandas de conocimiento pertinente con sus necesidades para ser aplicado en sus procesos productivos.

Se está incrementando la necesidad de desarrollar en el ámbito empresarial, un nuevo tipo de capital, el capital in- 
telectual, que requiere como insumo fundamental para su construcción, el conocimiento generado a nivel intra o extrorganizacional.

Para que el sector empresarial pueda desarrollar condiciones que imput sen la conversión de conocimiento en capital intelectual es necesario que se transforme en una organización capaz de asimilar conocimiento y consolidar mecanismos de autoaprendizaje.

Este último señalamiento constituye el elemento central a partir del cual se construyen las diferentes argumentaciones, por tanto, representa el tema objeto de estudio. El propósito general es aproximarse a la generación de ciertas explicaciones de orden teórico-conceptual que permitan lograr una amplia comprensión del tema objeto de estudio:La asimilación de conocimiento y el autoaprendizaje en organizaciones del sector empresarial; el cual se cumple a través de los siguientes objetivos:

1. Transferir los elementos característicos de la perspectiva biológica evolucionista al proceso de generación de conocimiento en las organizaciones del sistema social.

2. Explicar la producción y transferencia de conocimiento entre las organizaciones del sistema social.

3. Analizar el autoaprendizaje y la asimilación de conocimiento en las organizaciones del sector empresarial con base en un proceso de transferencia de los elementos característicos de ciertas imágenes metafóricas.

4. Inferir algunas hipótesis explicativas sobre el comportamiento de las organizaciones del sector empresarial a partir del autoaprendizaje y la asimila- ción de conocimiento, que representen un aporte al análisis y discusión sobre la Teoría Organizacional.

El trabajo se aborda desde cuatro grandes perspectivas. En un contexto de mayor generalidad, las dos primeras intentan explicitar algunos fundamentos teóricos-conceptuales que conforman el marco referencial de sustento a la producción y transferencia de conocimiento entre organizaciones del sistema social.

La tercera perspectiva, en un plano más específico, considera las organizaciones del sector empresarial como espacios capaces de asimilar conocimiento y participar en el diseño de estrategias que permitan fortalecer un proceso de autoaprendizaje permanente en los actores e instancias institucionales. En correspondencia con este planteamiento, se establece transferencia de los principales elementos característicos de ciertas imágenes metafóricas con la finalidad de generar explicaciones pertinentes con el objeto y ámbito de estudio. Concretamente se trabajan las organizaciones como sistemas abiertos, cerebros y sistemas culturales.

La última de las perspectivas refiere los principales resultados explícitos de un estudio de esta naturaleza. En este sentido, se presenta un conjunto de hipótesis explicativas relacionadas con el tema abordado que se pretende constituyan aportes al análisis y discusión sobre la Teoría Organizacional, con la intención de que se transformen en argumentos de origen para nuevas construcciones en un campo de tan variables, complejas y profundas formas de comportamiento.

El estudio está centrado en una fase de investigación y elaboración teóri- 
ca, donde a partir de un tratamiento de naturaleza holística se van abordando las diversas posturas con la finalidad de identificarlas, analizarlas e interpretarlas en relación con el objeto de estudio. Por sus propósitos, el trabajo tiene en primer lugar una intención explicativa cuando se pasea por diferentes perspectivas donde puede ser contextualizado el tema y en segundo lugar, demostrativa a través de un proceso de transferencia de los diferentes argumentos que se esgrimen alrededor de cada una de las perspectivas manejadas y en correspondencia con los aspectos que son investigados. La interacción entre ambos propósitos permite aproximarse a una estimación sobre el comportamiento futuro del sector empresarial a través de la definición de ciertas hipótesis explicativas.

Con base en los planteamientos originales de Peirce (1931-1958), el método de investigación de naturaleza lógico-formal que se utiliza, básicamente es la inferencia abductiva. Su aplicación mediante analogías y transferencias lleva a estructurar una serie de construcciones teóricas e inferir hipótesis, como hechos de una clase que parten de hechos de otra clase, pero que están íntimamente relacionados. Este método lógico de estudio y análisis conduce a transitar un proceso investigativo que permite ir más allá del efecto de la causa, de manera organizada, lógica y coherente, de tal forma que se explique dicha causa, y lo más importante aún se introduzcan nuevas ideas y razonamientos.

Al respecto resulta importante indagar acerca de:
- ¿Cómo las formas de pensamiento pueden usarse de manera práctica para interpretar y comprender las situaciones específicas del comportamiento organizacional, en relación con el consumo del conocimiento y dar forma al diseño y estructura de un espacio innovador?

- ¿Cómo las organizaciones del sector empresarial incluyen un sistema de procesamiento de la información, que puede ser experto en ciertas formas de aprendizaje?

- ¿Hasta que punto las organizaciones del sector empresarial pueden asumirse como un fenómeno "racional" que define de forma casi exclusiva sus objetivos y metas en función de asimilar conocimiento, fortalecer el autoaprendizaje y en consecuencia incrementar su capital intelectual?

- ¿En qué medida las necesidades y expectativas de las organizaciones del sector empresarial determinan las características del conocimiento que va ser asimilado e incorporado en sus procesos productivos?

- ¿Cómo la perspectiva biológica evolucionista, la imagen metafórica cultural, e igualmente la organización como cerebro y sistema orgánico abierto, contribuyen a explicar el comportamiento organizacional empresarial en relación con la asimilación y conversión del conocimiento generado en otros espacios sociales con la finalidad de fortalecer el autoaprendizaje de los actores e instancias institucionales? 


\section{Perspectiva biológica evolucionista como contexto referencial para explicar la generación de conocimiento en organizaciones del sistema social}

Para atender el proceso de construcción y comprensión del conocimiento que se genera en las organizaciones del sistema social, se puede considerar una perspectiva biológica evolucionista.

Si se establece analogía con procesos biológicos, uno de los elementos característicos del mundo viviente es su uniformidad, en cuanto a que existe un paralelismo en la composición química, organización y mecanismos funcionales de todos los seres vivos. Dichos organismos, atraviesan cambios graduales que determinan transformaciones radicales en el transcurso de los tiempos geológicos para llegar al estado de diversificación que existe actualmente. De allí que ambas características uniformidad y diversificación, son la base del concepto de evolución, lo que se traduce en que los seres vivos han experimentado modificaciones en el tiempo que han dado lugar a numerosas variaciones a partir de ancestros comunes.

Al igual que la evolución biológica la construcción del conocimiento como proceso, necesita considerar la gran diversidad de ideas que son producto de los datos e información que el individuo va recibiendo y sobre la cual es necesario actuar a través de un proceso de selección para lograr la adaptación y supervivencia. Ello se expresa tanto a nivel del individuo como de las organizaciones.
Considerar el conocimiento científico como producto de la actividad del individuo y las organizaciones, conduce a pensar en la necesidad de que su creación y reinvención se haga de manera permanente con la finalidad de que se logre la adaptación a un contexto cambiante y de acelerado desarrollo. Es lo que los científicos evolucionistas Darwin y Wallace llamaron la teoría de la selección natural.

Sus postulados teóricos pueden ser transferidos al caso concreto de la producción del conocimiento. Considerar la generación de conocimiento como proceso requiere contar con una base de información que sea capaz de internalizarce por el individuo y por la organización, para reflexionar acerca de la misma y estructurarla a nivel mental. Se podría pensar en la necesidad de que tanto individuos como organizaciones definan factores de selección para responder a esa "lucha por la existencia" que se presenta en el espacio organizacional donde se está produciendo el conocimiento.

Estos factores de selección estarán relacionados con la manera como se establezcan niveles de correspondencia entre la percepción de datos e información que están presentes en el mundo de los hechos y la representación que se haga de los mismos, en el mundo de las ideas. Existen en esta postura elementos implícitos de la perspectiva biológica evolucionista, cuya principal tesis relacionada con la selección está presente en los niveles de complejidad que deben abordarse al construir el conocimiento. Ello se refleja de manera consciente o inconsciente en la actuación de los sujetos y organizaciones que transitan el proceso, 
cuando atraviesan progresivamente fases de observación, percepción, abstracción, reflexión, organización mental, conferir significados, y reinterpretación de una situación manejada como información y que sujeta a cambios secuenciales, constituye fuente para la producción de conocimientos. Allí está presente una postura evolutiva.

Sin embargo, un análisis del comportamiento que pueden manifestar las organizaciones productoras de conocimiento desde esta perspectiva, implica atender a la definición de prioridades de acción, en correspondencia con las necesidades de producción de conocimiento que son demandadas a nivel intra y extraorganizacional. Las instituciones que exhiban una mayor capacidad para variar sus patrones de comportamiento y hacer los ajustes pertinentes no solo en lo que a producción de conocimiento se refiere, sino también en relación con las diferentes funciones que desarrollan, se verán favorecidas y lograrán su adaptación al ambiente.

Es precisamente la capacidad de las organizaciones para desarrollar mecanismos de adaptación lo que permitirá su supervivencia. Desde este punto de vista, se estaría considerando la evolución de estas entidades en atención al desarrollo de un ciclo biológico que incorpore estrategias de acción que permitan regenerar sus procesos en atención a requerimientos externos.

Conforme el medio cambie, las organizaciones van asumiendo nuevas formas de adaptación, y la acción del proceso de selección a través de largos períodos de tiempo, conducirá a la aparición de otras manifestaciones de comportamiento. En este caso concreto, se podría inferir como principal producto de la evolución contextual la emergencia de la sociedad del conocimiento, como expresión del paradigma científico - técnico propio de estas últimas décadas.

Se asume así el conocimiento y el comportamiento de individuos y organizaciones que producen el conocimiento como un proceso que aunque cambie permanentemente mantiene ciertas características esenciales que se transmiten de una generación a otra de individuos, o de una organización inicial a una organización emergente. Acurero (1995:29), indica que el contenido de la ciencia es un proceso de transmisión, que relaciona las diversas generaciones de sujetos que en el tiempo hacen la ciencia y construyen el conocimiento, de manera tal que quienes están aprendiendo pueden partir de la reconstrucción de conocimientos y procedimientos organizacionales establecidos, para estructurar su propio conocimiento, atendiendo a las posibles variaciones que se presentan en cuanto a las disciplinas o áreas del saber humano en las que se esté trabajando; asumiéndolas en un esquema propio.

Es decir que la generación de conocimiento demandará por parte de las organizaciones capacidades para repensar, recrear, reinventar, reintegrar y reordenar insumos, procesos y productos. Se transfiere el término replicación desde el campo biológico evolutivo como posibilidad cierta a partir de la cual se puede estructurar el conocimiento, implicando con ello la existencia en los sujetos de canales que lo capaciten para transmitir sus estructuras funcionales a sucesivas replicaciones teóricas - conceptuales de alto nivel de abstracción, que son las ideas. 
Ahora bien ¿cómo ser coherentes con una postura biológica evolucionista, cuando ésta, matiza que deben darse secuencias, gradualidad y transición entre etapas para llegar a ciertos estadios o niveles de desarrollo, que parte de unidades individuales y organizacionales cuya producción y transferencia de conocimiento ocurre en contextos dinámicos y cambiantes? Se podría pensar en un sentido contradictorio de esta perspectiva en relación con la propia naturaleza de lo que es el campo organizacional.

Naturalmente en la realidad siempre existen fuerzas perturbadoras que at teran el equilibrio de los individuos y organizaciones. Es allí donde se debe considerar la materia prima de la evolución biológica, representada por las mutaciones. Así como éstas producen variaciones hereditarias, que luego por un proceso de selección eliminan aquellas que son desfavorables, orientando la evolución en el sentido de elegir los organismos mejor dotados para adaptarse a nuevas condiciones ambientales, dentro del comportamiento de individuos $u$ organizaciones van aparecer elementos que alteran el curso normal de ocurrencia de los acontecimientos.

En este sentido deben considerarse elementos de la Teoría del Caos (Kosko 1995:110; Gleick 1998: 16), como postura que trata de explicar la emergencia de una serie de factores que van a influenciar de manera determinante los procesos individuales y organizacionales, de tal forma que dentro de la evolución que experimenten los sujetos, haya cabida para transformaciones radicales, ante los requerimientos de orden intra y extracontextual.
Desde esta óptica se asumen aspectos que permitan explicar las transformaciones que de manera generalmente imprevista se presentan durante el proceso de construcción del conocimiento, relacionadas fundamentalmente con la actuación combinada de factores externos e internos a los actores e instancias involucradas.

En correspondencia con los argumentos precedentes, dentro del proceso de generación del conocimiento el caos va a ser expresado en correspondencia con lo que filósofos de la ciencia como Kuhn (citado por Padrón 2000), denominan anomalías o inconsistencias, lo que conducirá a saltos o rupturas paradigmáticas. Se hace necesario identificar los principales espacios donde puedan ocurrir sorpresas, lo que dentro de esta concepción teórica es denominado como incertidumbre, con la finalidad de definir trayectorias de acción que permitan anticiparse a eventos futuros logrando la adaptación y supervivencia.

La teoría del caos como sustento para explicar los grandes y revolucionarios cambios o sea la transformación en el tiempo de los individuos, organizaciones y entorno en relación con la producción de conocimiento se manifiesta en los niveles cada vez más crecientes de información, cuyo manejo mental, demanda la incorporación de esquemas mentales amplios al proceso de generación del conocimiento, de tal forma que su impacto en el estudio de la realidad permita definir estrategias que faciliten la interacción con los cambios, transformaciones y el contexto donde se presentan. 


\section{Producción y transferencia de conocimiento entre organizaciones del sistema social}

Es importante atender la manera como el individuo, las organizaciones y la sociedad en su conjunto asumen el proceso de generación y transferencia de conocimiento en calidad de productores, usuarios o beneficiarios directos e indirectos de sus efectos.

En este sentido resulta útil señalar, que el conocimiento ha existido siempre, desde que el hombre empieza a poblar la tierra, y es que precisamente el conocimiento, si se asume como una cualidad, en una concepción más simplista, se podría afirmar, que es inherente al ser humano, por su propia condición. Cuando el individuo, como ente particular o miembro de una organización, en su necesidad de adaptación y supervivencia, empieza a idear ciertos mecanismos que permitan el logro de tal propósito de manera consciente o inconsciente, está contribuyendo a generar conocimiento.

Sin embargo el conocimiento como actividad humana a nivel organizacional exige una mayor elaboración, que debe atender su esencia, la búsqueda de su origen, es decir, asumirlo como proceso cíclico estructurado, más que como resultado.

El proceso de construcción de conocimiento demanda lineamientos de racionalidad que son propios del individuo como unidad productora del mismo o de las organizaciones como unidades de grupo que potencializan a través de diferentes mecanismos dicho proceso. Es precisamente este carácter, uno de los elementos que va a demarcar el tipo de conocimiento generado y que va a llevar al logro de los propósitos que se han predeterminado. Al respecto es importante considerar el conocimiento como producto de un contexto donde los actores interactúan y forman comunidades de trabajadores de conocimiento. Lo que Kuhn llama científicos organizados.

En razón de lo señalado, el conocimiento va a ser conceptualizado en función del paradigma en el cual vaya emergiendo. Esto significa que sus elementos y características definitorias, serán precisadas según el momento histórico - temporal que se esté viviendo. En este sentido, en el paradigma científico- técnico que enmarca el desarrollo de la sociedad actual, se está expresando una nueva realidad, que no se limita a la transferencia del poder entre espacios sociales 0 políticos, sino que los envuelve, y tiende a una gran transformación, que se conoce como la revolución del conocimiento.

En esta nueva era, el conocimiento adquiere otros significados que estarán en correspondencia con su comportamiento en los procesos de los que forma parte. Se asigna al conocimiento una gran dimensionalidad que incluye verdades, creencias, perspectivas, conceptos, juicios, expectativas, metodologías y saber como. El conocimiento va a ser usado para recibir información, para reconocer e identificar, analizar, interpretar, evaluar, sintetizar, valorar y decidir, adaptar, planificar, implementar y monitorear para actuar. De acá se desprende la amplitud del conocimiento como proceso que implica diferentes niveles de complejidad durante su estructuración.

Se concibe la producción de conocimiento como un proceso cíclico que cu- 
bre varias etapas. Dicho ciclo puede darse de manera completa a nivel interno en una sola organización, o desarrollar algunos de sus momentos a través de la interacción entre dos o más organizaciones del sistema social. La producción de conocimiento como proceso requiere contar con una base de información que una vez internalizada por el individuo o equipo de trabajadores del conocimiento, permita reflexionar acerca de la misma, organizándola mentalmente, tratando de lograr un alto nivel de correspondencia entre la percepción que se logra del mundo de los hechos, y la representación que se haga de la misma en el mundo de las ideas. Todo esto será complementado con el significado que el sujeto le asigne a la información recibida, lo que permite su reinterpretación y transformación. Ello traduce un proceso sistemático, progresivo que implica la observación, percepción, abstracción, reflexión, organización mental, conferir significados, y reinterpretación de una situación manejada como información y que sujeta a transformaciones, constituye el insumo principal para la producción de conocimiento.

Cuando dentro de la organización se empiezan a dispersar ideas, sin propósitos ni regulaciones definidas, se inicia la divulgación, que constituye germen para producir conocimiento. Se complementa con la interacción entre equipos mediante un proceso comunicacional a través de generar y compartir cierta información que lleve a alcanzar un aprendizaje mutuo, lo que Senge (1993: 296) denomina el aprendizaje en equipo. Se asume así la comunicación a partir de la convergencia o divergencia de criterios de intercambio y procesamiento mediante ciertos meca- nismos con el fin de producir un determinado conocimiento.

La transferencia de conocimiento es considerada de manera bidireccional o multidireccional a partir del intercambio entre las organizaciones, específicamente entre los trabajadores del conocimiento y sus actividades de investigación y desarrollo que crean una innovación y los usuarios de la nueva idea. Dicha transferencia se materializará en la asimilación por una de las partes, los usuarios o consumidores, del conocimiento producido. Se conduce a una serie de intercambios, con el propósito de lograr una comprensión mutua acerca del significado y propósitos de dicho conocimiento.

Se podría a través de un ejemplo comprender mejor el sentido de la transferencia. Se estaría hablando de dos sujetos ubicados en dos ámbitos organizacionales diferentes. En el espacio organizacional del primer sujeto se tiene una gran responsabilidad, como es percibir y explicar una situación, a manera de información, y procesarla a través de los niveles de complejidad mental ya señalados. Es precisamente en esta organización emprendedora donde se gesta un conocimiento que resulta de creaciones, innovaciones, creatividad e iniciativa para enseñar.

Ahora bien, es importante determinar las vías a través de las cuales el conocimiento producido en la primera organización, va a ser transferido a los sujetos de la segunda organización. Para ello será necesario crear una infraestructura de sustentabilidad, que tendrá bajo su responsabilidad definir lineamientos basados en estrategias y acciones que viabilicen la transferencia y respondan a necesidades y requerimientos presentes en 
el espacio de la segunda organización. Acá ocurren las transformaciones propias del proceso de aprehensión y transferencia del conocimiento, ya que es donde reside la capacidad de aprendizaje y asimilación (educación y entrenamiento), que a través de los mecanismos más idóneos permiten la total transferencia.

La transferencia de conocimiento entre organizaciones del sistema social será desarrollada como un proceso que demanda la intervención de una creación $y$ fuente de conocimiento, el tratamiento $y$ transformación del mismo, su difusión y aplicación, lo que puede darse a través de su valoración económica y social.

\section{La asimilación de conocimiento y el autoaprendizaje en las organizaciones del sector empresarial}

El nuevo paradigma científico - técnico en que se enmarca el momento actual, determina la importancia de analizar las nuevas necesidades y tendencias que presenta el sector empresarial relacionadas con la asimilación de conocimiento innovador para ser aplicado en sus procesos productivos.

Es el conocimiento producto de las actividades desarrolladas en otras organizaciones del sistema social un insumo para que el sector empresarial fortalezca sus procesos y logre maximizar sus ganancias económicas. De allí que se esté incrementando la necesidad de desarrollar en este espacio un nuevo tipo de capital, el capital intelectual. Dixon y Ross (2000:381) consideran que se dispondrá de mayores ventajas competitivas, cuan- do las instituciones diseñen estrategias que permitan la adquisición de conocimiento de tal forma que se transformen en organizaciones no solo capaces de asimilar conocimiento sino también consolidar mecanismos de autoaprendizaje.

Con base en lo antes referido, el análisis de las organizaciones del sector empresarial debe hacerse considerando la influencia ejercida por un contexto muy bien definido del que forma parte, representado por el sistema social. En su dimensión estructural y funcional comparte características y elementos que pueden ser comunes con las demás organizaciones aprehendidas en este ámbito.

El comportamiento de la empresa como unidad inteligente capaz de asimilar conocimiento, puede ser explicado bajo un enfoque de sistema orgánico abierto. Desde este punto de vista, se considera la empresa dentro de un conjunto de organizaciones que conforman el sector productivo y en una dimensión más amplia el sistema social.

De allí que para estudiar la empresa como organización capaz de asimilar conocimiento, es necesario establecer analogía entre su comportamiento y el funcionamiento de los organismos vivos, ya que se presentan al igual que éstos, en un medio ambiente del cual dependen para satisfacer sus variadas necesidades.

En este orden de ideas es importante identificar las necesidades que presenta la organización empresarial en relación con la producción y consumo de conocimiento, el proceso de interacción individuo-organización-entorno, su ciclo de vida, los factores que influyen en su salud y desarrollo, y las relaciones entre los individuos e instituciones como espe- 
cies o grupos de especies, así como también, los demás miembros de las poblaciones y el medio ambiente.

Se definirán las poblaciones como una forma visible donde convergerán las especies para su estudio, atendiendo al deber ser más que al comportamiento individual; al de la especie como ente teórico cuya base física real estará determinada por el conjunto de individuos que la componen y que conforman un determinado biotopo, representado en este caso por el ámbito organizacional empresarial. Esto será complementado con los necesarios cambios y transformaciones que experimenta cada individuo resultado del proceso evolutivo, para poder adaptarse a su ambiente.

De tal manera que es el ambiente, a nivel intra y extrorganizacional, como conjunto, quien determina e influencia estos cambios, primero en las organizaciones como unidades y luego en las poblaciones.

Si se asume el contexto social como una macropoblación donde compiten los diferentes segmentos que hacen vida en las diversas áreas del quehacer humano, se tiene que comprender que cada ámbito económico, político, académico, cultural, conforma una población donde existe un conjunto de organizaciones que comparten características esenciales, en función de ciertos criterios, como serían necesidades, expectativas, actividades que desarrollan, procesos que ejecutan, y resultados que obtienen.

Las organizaciones del sector empresarial en razón de la asimilación de conocimiento, funcionarán como sistema orgánico abierto cuando logran incorporar recursos de su entorno (interno y ex- terno), procesar estos recursos y generar determinados productos que vayan a satisfacer requerimientos de las demás organizaciones que comparten el sistema social. Surge un círculo de interacción cuyo flujo es permanente entre individuos, organizaciones y entorno.

Se puede precisar la correspondencia entre las organizaciones del sector empresarial con otros espacios cuya concepción y propósito sea similar o diferente en relación con la asimilación de conocimiento, como interdependientes estratégicamente. En el primero de los casos, se alude a todas las empresas como parte de una población única (el sector empresarial), que ocupan el mismo estrato en la escala evolutiva (organizaciones estratégicamente interdependientes cuyo sistema de relaciones fluye horizontalmente), que pueden competir unas con otras para la obtención de recursos y la disponibilidad de bienes y servicios con características comunes. En segundo termino, la empresa como parte de una población en relación a organizaciones de concepción generalmente diferente puesto que pertenecen a otra población, estableciendo un sistema de relaciones piramidal que desde el punto de vista evolutivo se ubican en estratos diferentes y atienden actividades diversas (organizaciones estratégicamente interdependientes cuyo sistema de relaciones fluye verticalmente). En ambos casos la asimilación de conocimiento, debe convertirse en la estrategia que permita la competencia y la adaptación.

Cuando se habla de competencia, para utilizar un término con significado biológico y ecológico muy preciso, se hace referencia a la necesidad de que la 
organización empresarial considere la asimilación de conocimiento como estrategia que más que competir en el sentido estricto de la palabra, le permita convertirse en un espacio inteligente a partir de diversos procesos como la negociación o concertación.

La tesis central enfoca la naturaleza de la cooperación interorganizacional (Espinoza 1999) como mecanismo que contribuye a delinear ámbitos institucionales muy exitosos, es decir a establecer una simbiosis mutual.

Cuando se consideró la postura evolucionista para explicar la generación de conocimiento en las organizaciones sociales, se identificó la secuencia de replicación como el proceso a partir del cual se produce la transmisión de estructuras funcionales, representadas por las ideas que concebidas a nivel mental constituyen elemento fundamental para construir el conocimiento. La replicación secuencial a partir de las ideas, necesita canales que permitan su procesamiento de tal forma que se expresen en productos como el conocimiento generado y transferido. Estos canales están representados por el cerebro del individuo y sus variadas conexiones neuronales dístales que procesan la información, generan ideas, producen conocimiento y permiten su asimilación.

Estudiar la organización empresarial como espacio para la asimilación de conocimiento y el autoaprendizaje de sus actores e instancias, puede hacerse interpretando su funcionamiento a partir de un proceso de analogía con el cerebro humano.

Asumir una concepción novedosa en este espacio, conduce a pensar la organización empresarial como cerebro, concibiéndola como una nueva forma de organización, donde el conocimiento, su asimilación, y el autoaprendizaje sea la iniciativa que permita la dispersión de las capacidades individuales y organizacionales a través de todas las instancias establecidas dentro de este ámbito.

Morgan (1996), señala que las organizaciones pueden concebirse como sistemas de procesamiento de la información capaces de aprender a aprender, así como también diseñarse a partir del reflejo de principios holográficos y cibernéticos.

A partir de estos planteamientos, las organizaciones del sector empresarial estarán en capacidad de recibir y procesar información, es decir que deben presentar condiciones de sustentabilidad para asimilar conocimiento y generar el autoaprendizaje.

Desde esta óptica la organización empresarial será considerada como un sistema cognitivo, que incorpora estructuras de pensamiento y actuación basadas en la inteligencia y el aprendizaje. Esto conducirá a tomar decisiones en función de un análisis organizacional que tome en cuenta factores internos y externos al proceso de asimilación de conocimiento y posterior transformación como parte de los mecanismos de producción.

El surgimiento de nuevas capacidades en la empresa producto del trabajo en equipo, puede ser analizado desde la perspectiva cibernética. Esto significa, que se identificarán lineamientos de acción que contribuyan a producir conocimiento a partir del conocimiento que ha sido asimilado, es decir, a generar un proceso cognitivo dentro de la organización empresarial como sistema, atendiendo a 
criterios de autorregulación y autoaprendizaje, a partir del intercambio y la interacción permanente.

La cibernética en este contexto permite ir haciendo ajustes de manera progresiva, de tal forma que el proceso de asimilación y autoaprendizaje, sea consecuencia de la toma de decisiones por parte de los actores involucrados y se refleje en la mejora de los productos que se generen ofreciendo respuesta a las demandas de los usuarios que pueden encontrarse en la misma empresa o en cualquier otra organización del sistema social.

Morgan (1996), plantea la visión holográfica, como una imagen que contiene toda la información necesaria para que ocurran ciertos procesos en correspondencia con el funcionamiento de las organizaciones como cerebros. Se consideran las capacidades requeridas por la totalidad institucional como presentes en cada una de sus partes, permitiendo un aprendizaje y la auto-organización basada en el funcionamiento permanente del sistema, aún cuando alguna de sus partes deje de hacerlo.

En este caso concreto se asume la asimilación de conocimiento como una capacidad propia de individuos y organizaciones. Los actores empresariales participan del fortalecimiento de estrategias que impulsen su aprendizaje cuando intervienen en la conformación de equipos de trabajo, de tal manera que mediante la asimilación y compartición de conocimiento, se cree un sistema conexo entre todos y cada una de las instancias institucionales con el fin de generar autoaprendizaje, co-aprendizaje y en consecuencia un crecimiento conjunto del ámbito pro- ductivo con un alto impacto en el medio donde se haya aprehendido el mismo.

Se asumirán las organizaciones del sector productivo como consumidoras de conocimiento en permanente proceso de aprendizaje e innovación, y eso solo será posible si se concibe la empresa como una unidad inteligente que desarrolla una infraestructura de sustentabilidad para transformar el conocimiento que recibe, como producto de las actividades de otras organizaciones del sistema social, en capital intelectual.

El análisis de las dimensiones teóricas-conceptuales que sustentan la configuración de capital intelectual a nivel de la organización empresarial, requiere la identificación de una serie de características que definen el perfil de este sector en correspondencia con sus modelos de comportamiento de orden cultural.

Específicamente en este contexto, la estructura y cultura organizacional atiende al modelo ideológico en el que subyacen los patrones conductuales de sus actores e instancias. Dicho referencial ideológico considera las principales necesidades e intereses, las fortalezas y oportunidades, así como las debilidades y amenazas, que hacen de este ámbito un contexto muy particular.

Esta particularidad ha determinado a través del tiempo, la manera como estos espacios se crean representaciones de las demás organizaciones del sistema social, y en consecuencia han influenciado la forma y motivos de relación con las mismas.

Se contextualiza la argumentación en la imagen metafórica de la organización empresarial como fenómeno cultural, 
con el fin de aproximarse a un nivel de racionalidad que incorpore a la discusión el valor de los significados que son compartidos en la actuación de actores e instancias organizacionales, así como también la reinterpretación que debe hacerse de la naturaleza y significado de las relaciones entre la empresa y el entorno. Es decir, que a través de un proceso de transferencia se crean las explicaciones que permiten a partir de ciertas reglas, conceptos y procedimientos interpretativos, estructurar la realidad organizacional en correspondencia con la disposición de asumir el conocimiento e insertarlo en sus procesos característicos, a través de su conversión en capital intelectual.

La configuración de capital intelectual a nivel de las organizaciones del sector empresarial requiere la definición de una infraestructura de sustentabilidad que considere elementos de orden estructural y funcional. Al respecto es importante puntualizar que el conocimiento producido en otros espacios sociales debe encontrar condiciones que permitan su incorporación en procesos claves de la empresa, como es la generación de capital intelectual.

Dicha infraestructura partirá de la interrelación entre las dimensiones individuales, de equipo, organizacionales e interorganizacionales. Se enmarcará el proceso de sustentabilidad en los nuevos modelos de comportamiento cultural que dichos espacios han venido asumiendo y que requieren aplicar estrategias gerenciales que permitan afianzar valores y crear la cultura del conocimiento basada en su difusión por todas las instancias, expresándose en la formulación de políticas institucionales y estrategias para el proceso de conversión.
Se asume la generación de capital intelectual a partir de la producción y asimilación de conocimiento, en el marco de una conformación en red que incluye, los actores de las organizaciones del sector empresarial y los otros espacios en interacción, la conformación de equipos de trabajo de alto desempeño, donde se distingan los diferentes roles que serán asumidos por los equipos, y la manera como se canalizará el proceso de conversión.

El capital intelectual resulta de articular de manera ágil, dinámica y flexible los activos organizacionales que constituyen el capital humano, el capital estructural y el capital relacional. Al hablar de activos organizacionales se está haciendo referencia a aquella porción de los recursos de los que disponen las organizaciones del sector empresarial y que dinamizan los procesos que suceden dentro de la misma.

En correspondencia con este último planteamiento, es necesario que la empresa fortalezca cualidades individuales, recursos de carácter físico, tecnológico y humano, con la finalidad de crear las condiciones para que los equipos y comunidades de trabajadores desarrollen sus actividades, a partir de procesos psicológicos cognitivos de aprendizaje secuencial y sistematizado propio de organizaciones flexibles. Existe la probabilidad de que la naturaleza de los grupos y equipos de trabajadores del conocimiento cambie significativamente cuando se tiene el capital como base para el desarrollo, y se conjuguen el conocimiento que es producto de otras organizaciones y los procesos propios del ámbito empresarial. 


\section{Principales resultados explícitos de investigación}

La aplicación de la metódica descrita brevemente en el primer apartado de este trabajo, lleva a inferir una serie de premisas que pretenden constituir en si mismas, hipótesis explicativas del comportamiento del tema objeto de estudio: la asimilación de conocimiento y el aut toaprendizaje en organizaciones del sector empresarial. La intención fundamental es que dichas premisas representen un sólido aporte, como punto de partida, a la discusión sobre la teoría organizacional y sus diversas implicaciones.

- Las diferentes formas de pensamiento de los actores organizacionales contribuyen a interpretar y comprender las situaciones específicas del comportamiento organizacional, en relación con el consumo de conocimiento, de tal forma que se internaliza la necesidad de transformar la empresa en un espacio innovador a partir de la incorporación de este conocimiento en sus procesos productivos.

- Las organizaciones del sector empresarial pueden asumirse con un alto $\mathrm{ni}$ vel de racionalidad que permite el desarrollo de sus procesos en función de la consecución de objetivos y metas relacionados con la conversión en sus espacios del conocimiento en capital intelectual.

- Los lineamientos de racionalidad que son demandados durante el proceso de construcción y transferencia del conocimiento son considerados propios del individuo como unidad responsable de su elaboración o de la organización como unidad responsable de definir estrategias potencializadoras de dicho proceso.

- La racionalidad en el proceso de producción y transferencia de conocimiento entre organizaciones del sistema social, estará determinada por el significado que los actores e instancias organizacionales compartan en relación con los propósitos que pueden ser asignados a dicho proceso.

- Las organizaciones del sector empresarial pueden convertirse en un ámbito donde se asimila el conocimiento producido en otros espacios sociales, con fines de convertirlo en capital intelectual.

- Las necesidades y expectativas de las organizaciones del sector empresarial determinan las características del conocimiento que va a ser asimilado e incorporado en sus procesos productivos.

- Las imágenes metafóricas de la organización como sistema cultural, como cerebro, la cibernética, el cerebro holograma y sistema orgánico abierto pueden ser transferidas para explicar el comportamiento organizacional empresarial en relación con la asimilación y conversión de conocimiento en capital intelectual.

- Para que las organizaciones del sector empresarial desarrollen condiciones que impulsen la conversión de conocimiento en capital intelectual es necesario que se transforme en una organización capaz de asimilar conocimiento y consolidar mecanismos de autoaprendizaje.

- Se establece una relación directamente proporcional entre la adaptación que puede experimentar una or- 
ganización a su ambiente y la capacidad de ésta para variar sus patrones de comportamiento.

- El aprendizaje de la organización es estructurado a partir de la asimilación de conocimiento que puede ser reconstruido a partir de ciertos procedimientos organizacionales establecidos en correspondencia con los cambios y transformaciones que emergen en las diferentes áreas del saber humano.

- El proceso secuencial, evolutivo y cíclico de producción y transferencia de conocimiento entre organizaciones del sistema social, considera la aparición de elementos alteradores en su curso normal de ocurrencia, propios del contexto intra o extrorganizacional.

- El proceso cíclico de producción y transferencia de conocimiento puede cubrir todas sus fases en una sola organización o desarrollar alguno de sus momentos a través de la interacción entre dos o más organizaciones del sistema social.

- La asimilación de conocimiento y el autoaprendizaje organizacional demanda un proceso comunicacional entre los diferentes equipos de trabajadores de conocimiento que permita a partir del intercambio y procesamiento de cierta información transformada en conocimiento, trascender la idea de "equipo" y trabajar en función de "comunidades" organizacionales del conocimiento.

- La tesis del fortalecimiento organizacional a partir de la asimilación de conocimiento y el autoaprendizaje demanda la creación de una infraestructura de sustentabilidad que trascien- da los aspectos estructurales e incorpore elementos de orden humano y relacional.

- Las organizaciones sociales constituyen sistemas cognitivos, cuyo funcionamiento está sustentado en modelos de pensamiento y actuación basados en procesos de aprendizaje a partir del desarrollo intelectual y de habilidades transferibles entre individuos e instancias organizacionales.

\section{Algunas consideraciones finales}

La investigación se concibió bajo un enfoque teórico - conceptual que consideró la utilización de ciertas imágenes metafóricas no exclusivamente como figura literaria sino como metodología que a través de un proceso de transferencia y analogía permitió explicar el comportamiento de las organizaciones del sector empresarial en relación con la asimilación de conocimiento y su capacidad de autoaprendizaje. Ello significa que dichas metáforas contribuyen a que se visualice de una manera más clara el complejo carácter de la vida organizacional.

Desde este punto de vista se brinda gran importancia a las imágenes trabajadas, alrededor de las cuales se construyen las argumentaciones correspondientes, de tal forma que viabilicen la comprensión del fenómeno organizativo, revalorizándolas en los procesos cognitivos y científicos. Permite la metáfora, como base de la escuela del pensamiento, interpretar y comprender el fenómeno organizacional en relación con la asimilación de conocimiento y el autoaprendizaje, constituyendo en sí misma un vaso co- 
municante entre los paradigmas como realidades alternativas y la construcción del hecho científico a través de la generación de teorías, producción de conocimiento y en consecuencia solución de problemas.

Las imágenes metafóricas como metódica para estudiar el comportamiento de la organización empresarial en relación con la asimilación de conocimiento y la capacidad de autoaprendizaje presentan gran flexibilidad y dinamismo. Ello significa, que dentro del trabajo se dejó abierta la posibilidad para lograr no sólo, un sentido de complementariedad e integración entre metáforas, sino también que se incorporó en la discusión y argumentación elementos de procesos investigativos mucho más rigurosos, que incluyeron métodos lógicos como la inferencia abductiva, y que se insertan en el racionalismo como postura paradigmática en un espectro de mayor dimensionalidad.

\section{Bibliografía Citada}

Acurero, Gladys (1995), Las Nuevas Fronteras del Conocimiento. Maracaibo. Estado Zulia. 80 pp. Ediciones Astro Data.

Dixon, N. y Ross, R. (2000), "El Ciclo de Aprendizaje Organizacional”. En La Danza del Cambio. Colombia. Editorial Norma. Bogotá, 381-389 p.p.

Espinoza, Rafael (1999), Naturaleza y Alcance de la Relación Universidad - Sector Productivo. Editorial de La Universidad del Zulia. Maracaibo, Venezuela. $176 \mathrm{pp}$.

Gleic, J. (1998), Caos: la creación de una ciencia. Barcelona, España. Seik Barral Editorial. 60 pp.

Kosko, B. (1995), "Pensamiento Borroso". La nueva Ciencia de la lógica borrosa. Barcelona, España. Editorial Grijalbo. 180 pp.

Morgan, Gareth (1996), Imágenes de la organización. México. D.F. Alfaomega Grupo Editor. 403 pp.

Padrón, José (2000), Temas para Seminario de Epistemología. Doctorado en Ciencias Humanas. La Universidad del Zulia. Venezuela.

Peirce, C.S. (1931-1958), Collected Papers. 8 Vols., C. Hartsorne, P. Weiss and A. Burks (eds), Cambridge, MA, Harvard University Press.

Senge, Peter (1993), La Quinta Disciplina. Buenos Aires, Argentina. Ediciones GRANICA. 490 pp. 